\title{
Criatividade e inovação: competências na gestão de enfermagem
}

\author{
Creativity and innovation: competences on nursing management
}

Creatividad y innovación: competencias en la gerencia de enfermería

\author{
Liliane Bauer Feldman', Rosa Maria Ruthes', Isabel Cristina Kowal Olm Cunha' \\ 'Universidade Federal de São Paulo, Grupo de Estudos e Pesquisas em Administração dos \\ Serviços de Saúde e Gerenciamento de Enfermagem (GEPAG). São Paulo, SP
}

Submissão: 01/12/2006

Aprovação: 03/04/2007

\section{RESUMO}

O presente artigo apresenta a importância da criatividade e da inovação nos serviços de saúde, distinguindo esses conceitos. Comportamento criativo é o aprimoramento de um elemento ou ação conhecidos, enQuanto inovação significa encontrar novas alternativas. Considerando-se as competências, ou seja, conhecimento, habilidade e atitude - CHA, compreende-se Que, estimulandose a criatividade e a inovação, a atuação do profissional de saúde será otimizada. A criatividade e a inovação são, portanto, elementoschave para o aprimoramento organizacional e para Que, especificamente, a Enfermagem encontre alternativas para solucionar problemas no âmbito profissional. Dessa forma, esta abordagem traz uma ferramenta estratégica no processo de gestão e um diferencial para o enfermeiro o Qual, ao criar ou inovar, se surpreenderá com seu potencial.

Descritores: Enfermagem; Difusão de inovações; Liderança; Criatividade.

\section{ABSTRACT}

This article presents the importance of the creativity and innovation on health services, distinguishing those concepts. Creative behavior is the improvement of an element or known actions; whereas innovation means finding new alternatives. Considering competences like knowledge, skill and attitude - KSA, it is understood that by stimulating creativity and innovation, the performance of the health professional will be optimized. Therefore, creativity and innovation are key elements for improvement and organization, and, more specifically, for Nursing to find alternatives for solving problems related to the occupation as a whole. In this way, this approach brings a strategic tool on the process of management and a differential for the nurse, which by innovating and creating will amaze herself with her potential.

Descriptors: Nursing; Diffusion of innovation; Leadership; Creativeness.

\section{RESUMEN}

El presente artículo presenta la importancia de la creatividad y de la innovación en los servicios de salud, distinguiendo estos conceptos. Comportamiento creativo es el mejoramiento de un elemento o acción conocidos, siendo Que innovación significa encontrar nuevas alternativas. Llevando en consideración las competencias, o sea el conocimiento, la habilidad y la actitud - CHA, se comprende Que, sé estimulando la creatividad y la innovación, la actuación del profesional de salud va ser optimizada. La creatividad y la innovación son, por tanto, elementos-clave para la mejora, organización y para Que, específicamente, la Enfermería encuentre alternativas para solucionar los problemas en el campo Que la profesión envuelve. De esta forma, este abordaje trae una herramienta estratégica en el proceso de gerencia y un diferencial para el enfermero el cual, al criar o innovar, se sorprenderá con su potencial.

Descriptores: Enfermería; Difusión de innovaciones; Liderazgo; Creatividad.

Correspondência: Liliane Bauer Feldman. Rua Aureliano Coutinho 149 - sala I I-26. Santa Cecilia. CEP 01224-020. São Paulo, SP. 


\section{INTRODUÇÃO}

A criatividade é um dos recursos mais fecundos para o homem, partindo da premissa Que este sempre procurou derrotar os seus inimigos atávicos como a fome, o cansaço, a ignorância, o medo, a feiúra, a solidão, a dor e até a morte ${ }^{(1,2)}$, utilizando-a. Alguns autores sugerem a utilização dessa competência, indicando ser essa uma das chaves para a descoberta de soluções novas para problemas antigos ${ }^{(2,3)}$. Exemplos do uso da criatividade são reconhecidos Quando um profissional costuma ser "fuçador", pensa e faz diferentemente, propõe e testa alternativas de solução, descobre o "pulo-do-gato", age com idéias.

Especialistas afirmam Que a criatividade é uma das competências mais fáceis de se encontrar no comportamento das pessoas nas organizações, sendo mencionada como comportamento criativo, ou de fazer melhor o Que já vinha sendo feito ${ }^{(3,4)}$. Este conceito difere do de inovação, isto é, do profissional Que procura caminhos ainda não percorridos, busca produtos e processos realmente novos, oportunidades de mercado, deseja criar tecnologias, inventar ou reinventar a roda, patentear produtos e ou processos ${ }^{(5)}$. No presente estudo, criatividade e inovação serão consideradas competências complementares. Percebe-se Que ambas são imprescindíveis no gerenciamento dos serviços de enfermagem, Quer seja aplicadas nas organizações públicas, privadas ou sociais.

A escassez de estudos sobre criatividade e inovação como competências do enfermeiro na gestão organizacional motivou a realização desta atualização. Além disso, como os autores participam do Grupo de Estudos e Pesquisas em Administração dos Serviços de Saúde e Gerenciamento de Enfermagem (GEPAG) da Universidade Federal de São Paulo, buscou-se identificar as principais competências para otimizar o desempenho do enfermeiro.

\section{DESENVOLVIMENTO DA CRIATIVIDADE E INOVAÇÃO}

No desenvolvimento amplo da criatividade e inovação percebese que a criatividade é o ato de criar: tirar do nada, transformar, educar, gerar, inventar, produzir, cultivar, instituir, fundar. Essas são as definições Que constam nos dicionários da língua portuguesa ${ }^{(6)}$, e delas podem partir todas as possibilidades existentes no re-criar ou inovar.

Considera - se que as habilidades criativas são aquelas que permitem ao indivíduo associar conceitos até então independentes e a conhecer novas maneiras de pensar ${ }^{(4)}$. A atitude criativa vem de uma necessidade inerente a todo o ser humano de crescer através de seu potencial interno. A pessoa criativa pode ser entendida como aquela que sabe Quem é, onde quer ir e o que deseja realizar. As descobertas e inovações em todas as áreas foram sempre feitas por indivíduos Que observaram e perceberam de uma maneira diferentes fatos Que todo mundo tinha como verdades inQuestionáveis ${ }^{(5)}$.

A Questão da criatividade precisa ser mais bem entendida. Criatividade não é sinônimo de inventar coisas desrespeitando normas, em que cada um faz o Que der vontade. Criar não é coisa de Quem não planeja e precisa improvisar para se sair das situações problemáticas $^{(7)}$. A criatividade precisa ser contextualizada através um olhar atento aos objetivos organizacionais, Que compartilha conceitos e métodos acerca das dimensões organizacionais da noção de competências, e interage com sua história, visão, negócio, missão, valores, princípios e estratégias.

A criatividade não é negar o pensamento racional, mas sim, partir dele para construir novas eQuações para os problemas e suas soluções. É ela Que potencializa a inteligência inaugurando novas maneiras de pensar o mesmo e às vezes, velho problema ${ }^{(7)}$.

Ser criativo é estar mais à vontade no mundo, mais rico de recursos pessoais. É estar mais vivo e motivado. É resgatar a autoestima. É surpreender-se consigo próprio. É humanizar-se. Saber acolher. A humanização é essencial nos processos de relacionamento da prática cotidiana de enfermagem e carece progressivamente da criatividade e da inovação na relação, paciente - enfermagem outros serviços.

A coragem é uma delas, é imprescindível para o ato de criar, de descobrir e de acreditar, pois o homem necessita de coragem para "vir a ser"(8).

Por isso a criatividade e a inovação são consideradas ferramentas do processo de gestão por competência, e são trazidas à baila para instrumentalizar os enfermeiros a vencer barreiras no ambiente de trabalho.

\section{CRIATIVIDADE E INOVAÇAO NO AMBIENTE DE TRABALHO}

Percebe-se Que vários são os fatores Que tem influência no conhecimento, na mobilização e no uso do talento criativo nas organizações. Muitos desses fatores residem no próprio ambiente de trabalho e podem apresentar tanto um caráter facilitador Quanto se constituírem agentes repressores da criatividade e ao seu aproveitamento $^{(2)}$.

Outros autores e teóricos ${ }^{(7,9)}$ compreendem a competência como o conjunto de conhecimentos, habilidades e atitudes- $\mathrm{CHA}$, necessárias para Que a pessoa desenvolva suas atribuições e responsabilidades usando da criatividade e inovação. Esse enfouue é pouco instrumental, pois o fato de as pessoas possuírem determinado conjunto de conhecimentos, habilidades e atitudes, não é garantia de Que elas irão agregar valor à organização colocando-as na prática.

O crescimento e a evolução das organizações precisa sair da mesmice, mas isso só acontecerá Quando abrirem espaço para o elemento chamado criatividade e inovação. Aquelas Que alavancam as soluções e superam medos e preconceitos, trazem mudanças Qualitativas no ambiente organizacional ${ }^{(10)}$. A criatividade e a inovação oxigenam o cotidiano das pessoas trazendo um hábito saudável para o ambiente organizacional, e sendo gradativamente transferido para outros contextos e outros ambientes. O mais interessante é Que a criatividade dá permissão às pessoas para Que se percebam criativas $^{(2)}$.

Descrever um clima apropriado à criatividade não é uma tarefa difícil. O grande desafio reside em promover um ambiente de trabalho onde haja espaço para o florescimento de novas idéias e congruência entre as necessidades do indivíduo e as demandas da organização(2).

É possível desenvolver a habilidade de ser criativo e aprender a aprimorar-se nessa prática. Existem algumas condições facilitadoras e desencadeadoras do processo e essas condições requerem uma 
revisão do próprio auto-conceito sobre o Que é criatividade e o Quanto se pode ser visto como pessoa criativa ${ }^{(1)}$. É da organização Que parte o incentivo às idéias, Quando os gestores abrem as portas para as sugestões e propostas dos colaboradores. Para isso, é necessário anteriormente, identificar os pontos críticos, potenciais de risco e conflito. Olhar as situações mais como desafios e sentirse motivado para enfrentá-las. Perder o medo de ser ridículo e do julgamento dos outros. Estimular a criatividade nos colegas de trabalho, dando oportunidades para se desenvolverem. Quebrar padrões de comportamento disfuncionais com assertividade. Sentirse orgulhoso de falar. Enquanto gestores, encontrar formas de reconhecer e gratificar os momentos criativos e inovadores do diaa-dia de sua equipe de trabalho( ${ }^{(9,10)}$.

A criatividade revitaliza as organizações estimulando a ousadia das pessoas o Que dá um salto Qualitativo nos produtos e serviços, facilmente percebidos pelos clientes internos e externos, familiares, fornecedores, público alvo usuário destes serviços ${ }^{(12)}$.

Para tal, o enfermeiro deve habituar-se a perguntar: de Que maneira posso fazer isto melhor, mais rápido, mais eficientemente? De que maneira posso melhorar o desempenho da equipe? Como posso agregar valor a missão organizacional?

Isto é comportamento criativo e inovador. É isso Que as instituições estão buscando de todos seus colaboradores. Desde o porteiro até o presidente. Deve-se procurar sair do trabalho solitário para o solidário, fazendo assim a inclusão de todos, pois a idéia criativa pode surgir de Qualeuer nível hierárQuico ${ }^{(13)}$.

Assim, a imaginação humana tornou-se a matéria-prima da era em Que vivemos. Outras fontes de competitividade, como capital e recursos naturais, sofrem da lei dos rendimentos decrescentes. Por outro lado, a criatividade e a inovação constituem uma das poucas fontes de competitividade cujo retorno é infinito ${ }^{(11-13)}$. Precisa-se de inovação em nossas produções e serviços, nas formas de relacionamentos, atrelados à criatividade para favorecer a entrega das competências com resultados tangíveis ${ }^{(12)}$. Pode-se dizer Que o enfermeiro é um profissional Que aplica essa competência, pois muitas vezes busca soluções imediatas e inéditas para prestar uma assistência segura $^{(14)}$, prevendo riscos e aprimorando a Qualidade ${ }^{(15)}$.

$\mathrm{O}$ processo criativo exige mente aberta, receptiva ao novo, equilíbrio nas emoções, flexibilidade e conhecimento do diferente, pois nossa atuação depende da estabilidade emocional, seguida da tomada de decisão ${ }^{(11)}$, pelo uso do pensamento convergente, buscando resultados Qualitativos e Quantitativos, utilizando criatividade, inovação e as competências ${ }^{(7.12)}$. Nota-se, portanto, Que a criatividade é algo surpreendente e útil, tanto para o criador, Quanto para a sociedade, tratando-se de um processo Que possui começo, meio e fim.

O processo criativo exige trabalho duro, disciplina, isto porque muitas vezes há bloqueios, medo e timidez para o pensar criar. Por outro lado idéias também surgem Quando a pessoa está brincando, desocupada, ociosa ou Quando se tem um comportamento curioso, ineuieto, por vezes incomodado. Neste aspecto, uma pessoa curiosa, poderá gerar idéias ou essa idéia irá surgir e passará bater freeüentemente na porta, mente do indivíduo. Assim as lacunas do pensamento estático serão preenchidas por necessidades e costumes Que, certamente, favorecerão a geração de idéias.

Relata-se Que existem ao menos três justificativas para o fato da criatividade estar sendo tão valorizada no mundo profissional contemporâneo: a competitividade cada vez maior, a grande velocidade das transformações e a valorização do empreendedorismo ${ }^{(8,12)}$; pois permite ao gestor da área a proposição de projetos inovadores para a busca de resultados novos e eficazes e de novas formas de comportamento e desempenho individual e organizacional. A atitude inovadora do gestor possibilita o desenvolvimento de atividades Que constituem desafios para a criatividade individual e coletiva, levando a um realinhamento grupal muito mais produtivo e prazeroso ${ }^{(13)}$.

\section{CRIATIVIDADE E INOVAÇÃO COMPETÊNCIAS DE ENFERMAGEM}

Todo e Qualquer ser humano tem criatividade, entretanto, normalmente não está acostumado a usá-la e, Quando faz, faz de forma mecânica. Contudo a natureza do trabalho do enfermeiro não é diferente. Ele, no entanto não o impede de ter idéias, de pensar diferente para simplificar métodos e procedimentos, melhorar sistemas, agilizar fluxos, reduzir burocracia, papelada, custos, controles mais eficientes. Organizar mais racionalmente é focalizar a criatividade e contribuir para agregar valor a sua profissão. Adicionalmente, é requerida do indivíduo a utilização das competências gerenciais: saber (conhecimentos), saber fazer (habilidades), saber-ser-agir (atitudes) como um jogo culminando muitas vezes na produção de obras e idéias importantes na revolução do saber-fazer da Enfermagem ${ }^{(14,15)}$.

Várias organizações de saúde, visando à Qualidade já se conscientizaram de que é no seu capital humano Que está o potencial criativo $^{(9,11)}$. Entretanto, os profissionais muitas vezes não sabem como organizar ou como aproveitar esse potencial criativo Que está disponível. Esse fato é comprovado pela Qualidade das idéias inesperadas que surgem de vez em Quando. Por Que então esperar as idéias de vez em Quando? Por Que não estimular a produção destas idéias no dia-a-dia?

Lembrar-se de Que só se conseguirá chegar a uma excelente idéia se tiverem muitas outras para optar fazer um grande brainstorming. Não é preciso uma grande idéia e sim uma idéia de grande resultado.Este poderá ser um caminho para a organização de saúde desenvolver o processo de gestão por competências ${ }^{(13,16)}$. Inclusive porque o mercado da saúde está bastante competitivo e se adequa a estes conceitos ${ }^{(11,12)}$.

A área da educação e da pesquisa em enfermagem tem oportunizado a geração de idéias por meio de técnicas pedagógicas e novos procedimentos utilizados pelos educadores ${ }^{(15)}$, como por exemplo, as dinâmicas de grupo. O uso de PDI - Plano de desenvolvimento individual do aluno, o portfólio, os trabalhos de conclusão de cursos - TCC e o plano de cuidados baseado em evidências são exemplos concretos da revelação da criatividade dos discentes com supervisão e estimulação dos docentes.

A criatividade deriva da falta de opções ou do descontentamento com as escolhas existentes. A criatividade desorganiza o mundo, pois gera novos caminhos, provocando a subversão da estabilidade anterior e esse é o motivo pelos Quais os indivíduos criativos são às vezes incompreendidos, criticados e até perseguidos em alguns ambientes. Eles subvertem, portanto, incomodam. Mas, se de um lado a criatividade e a inovação incomoda, de outro é ela Que abre caminho para as melhorias ${ }^{(2,12)}$. 
As pessoas nem sempre compartilham suas idéias, sentimentos ou experiências por medo de serem furtadas, por isso correm o risco de estacionarem suas experiências na gaveta, conseQüentemente permanecem somente na geração de idéias e deixam de lado o colocar em prática. Muitas produções cientificas deixam de ser executadas Quando isso ocorre.

\section{CONSIDERAÇÕES FINAIS}

A criatividade é fundamental na obtenção de propostas para o aprimoramento organizacional, pois influencia no comportamento das pessoas a curto, médio e longo prazo; para Que sejam encontradas alternativas de solução para problemas, conflitos e dificuldades pontuais e freqüentes entre gestores; e para que se possibilite às pessoas encontrar novos padrões diante de situações inesperadas facilitadas no ambiente amigável, estimulante e livre de censuras, no menor intervalo de tempo possível ${ }^{(16)}$.

A educação para o pensamento criativo é primeiro passo para a melhora do nível de inovação nas organizações. Trata-se de uma ferramenta estratégica do processo de gestão e um diferencial para o enfermeiro no gerenciamento da equipe de enfermagem, Que ao criarem ou inovarem se surpreenderão com seu potencial.

\section{REFERÊNCIAS}

I. De Masi D. Criatividade e grupos criativos. Rio de Janeiro (RI): GMT Editores Ltda; 2003.

2. Alencar ES. A gerência da criatividade. São Paulo (SP): Makron Books; 2002.

3. Daolio LC. Perfis e competências: retrato dos executivos, gerentes e técnicos. São Paulo (SP): Érica 2004.

4. Quinn ER, Thompsom PM, Faerman RS, MCGrath M. Competências gerenciais: princípios e aplicações. Rio de Janeiro (RJ): Elsevier; 2003.

5. Torrance EP. Criatividade - medidas, testes e avaliações. São Paulo (SP): Editora IBRASA; 1976.

6. Aurélio BHF. Novo dicionário da língua portuguesa. $2^{\mathrm{a}} \mathrm{ed}$. Rio de Janeiro (RJ): Ed. Nova Fronteira; 1986.

7. Dutra IS. Competências: conceitos e instrumentos para gestão de pessoas na empresa moderna. São Paulo (SP): Atlas; 2004.

8. Dutra JS, organizador. Gestão por Competências: um modelo avançado para o gerenciamento de pessoas. São Paulo (SP): Ed. Gente; 2004.

9. Lampoglia MA. Criatividade faz a diferença. [citado em: 12 Set 2006]. Disponível em: URL: http://www.criatividade.com.br

10. Schimidt BH. Gerenciamento criativo: planos e ferramentas para transformar sua empresa em um estúdio de criação. São Paulo (SP): Nobel; 2004.

1 I. Barret R. Libertando a alma da empresa: como transformar a organização numa entidade viva. São Paulo (SP): Editora Cultrix Amana-Key; 1998

12. Mussak E. Metacompetência: uma nova visão do trabalho e da realização pessoal. São Paulo (SP): Editora Gente; 2003.

13. Ruas R. Desenvolvimento de competências gerenciais e a contribuição da aprendizagem organizacional. In: Fleury MT; Oliveira IR, organizadores. Gestão estratégica do conhecimento. São Paulo (SP): Atlas; 2001.

14. Cianciarrulo TI. Instrumentos básicos para cuidar: um desafio para a Qualidade de assistência. São Paulo (SP): Ed. Ateneu; 2000.

15. D'Innocenzo M, Feldman LB, Fazenda NRR, Helito RAB, Ruthes RM. Indicadores, auditorias, certificações: ferramentas de Qualidade para gestão em saúde. São Paulo (SP): Martinari; 2006.

16. Santos KMAB, Silva MIP. Percepção dos profissionais de saúde sobre a comunicação com familiares de pacientes em UTIs. Rev Bras Enferm 2006; 59(1): 61-6. 